\title{
Self Defence Torch Light using Arduino
}

\author{
O Mahendar Singh Rajpurohit, K K Pradeep Raj, S Kabil Balan, R Priya
}

\begin{abstract}
It's observed that most of the crimes against women takes place during night-time. Only safety measure available for women during emergency is pepper spray which is often unconventional thus we came up with a solution for it. With the help of our high intensity torch light, women can flash it into the eyes of the person whom they suspect and since our pupil contract when exposed to bright light it causes loss of sight for a few seconds then that women could electrocute that person with the electrodes attached to it. This is an alternative to pepper spray since women can't keep pepper spray in hand all the time while walking in streets or roads but can have a torch light with them and the suspect will misjudge it with an ordinary torch light. With the help of Arduino and SIM808 GSM/GPS the position of women is sent as message to their guardians. Apart from it the flashing of light is controlled by Arduino. This is only a safety measure and can help girls from being harassed but apart from it initiative must be taken from every Indian to make India a better place to live for every women.

Keywords: GSM/GPS, SIM808.
\end{abstract}

\section{INTRODUCTION}

Ladies wellbeing and security has ascended to become plan of numerous ideological groups. The violations against ladies, as detailed by the National Crime Records Bureau of India, have expanded by $6.4 \%$ in 2012 . The insights at the NCRBI shows that a wrongdoing is submitted against ladies at regular intervals. As of late the wrongdoing are increasing in a disturbing rate. Around 244,280 wrongdoings against ladies were accounted for in India in 2012 alone. 2011 stamped enlisted grievances of 228,640 were ladies were exposed to viciousness. This is only a figure, as number of cases goes unregistered because of dread, social shame joined and smothered. With the figure bringing up that ladies and kids are exposed to such abominations, physical and sexual, there is a need to have a gadget that would assist them with alerting somebody in instances of crisis. The fundamental thought is to have ready frameworks as well as a gadget that would gather proof.

\section{EXISTING SYSTEM}

The possibility of the task is drawn from the Medical ready frameworks with Telehealth and telemedicine checking utilizing GSM and GPS innovation, where the GSM/GPS framework is utilized to alarm in the event of health related Emergency. In any case, this framework doesn't have a programmed include as proposed right now.

Revised Manuscript Received on April 25, 2020.

* Correspondence Author

O Mahendar Singh Rajpurohit*, Department of ECE Sri Krishna College of Technology Coimbatore

K K Pradeep Raj, Department of ECE Sri Krishna College of Technology Coimbatore

S Kabil Balan, Department of ECE Sri Krishna College of Technology Coimbatore

R Priya, Assistant Professor Department of ECE Sri Krishna College of Technology Coimbatore

(C) The Authors. Published by Blue Eyes Intelligence Engineering and Sciences Publication (BEIESP). This is an open access article under the CC BY-NC-ND license (http://creativecommons.org/licenses/by-nc-nd/4.0/)
Constant ready framework for home observation is another checking framework. Here a mind boggling framework joined to PC at home is utilized. It has gathering of sensors appended and a focal framework which persistently screens the locale. On interruption it sends an email and SMS to the stipulated id and Mobile Station individually. It is wired and not compact. There are various Android applications which manage a similar reason. State recognize a fall and send message or alarm on turning ON the application. Another disadvantage here is that the greater part of these must be started physically, which may make the assailant aware of keep the unfortunate casualty from doing as such. An individual can likewise be recognized utilizing the last area (base station) from which a call/SMS/MMS was started from the specific Mobile station. This isn't an idiot proof framework in such a case that the assailant controls with the injured individual's telephone that would lead the examination to an alternate bearing. A conspicuous technique for distinguishing an individual under risk is utilizing GPS framework. We have consolidated the equivalent in our model as well. By utilizing GPS framework we can get exactness as high as 40 meters.

To give a programmed highlight to the model enthusiastic sensors were considered. The issue with bit is that it isolates human feeling to upbeat and miserable; this offers ascend to bogus positives by turning ON the framework in any event, when the client is genuinely low. Additionally, the sign must be more than the edge which is client subordinate. Under pressure human salivation discharges Salivary Alpha Amylase. In any case, the nearness of Salivary Alpha Amylase can be identified distinctly under lab state of $-10^{\circ}$ Celsius temperature and need at any rate $10 \mathrm{ml}$ of salivation for the test. Flex sensors are the most affordable and the best sensors accessible in the market. There are sensibly enormous quantities of items accessible in showcase utilizing the equivalent. The upside of Flex sensor lies in the way that they are minimal, less expensive, exact and can be utilized around a million twists. This being a promising element we fuse the equivalent in our framework. We can utilize Fall discovery sensor. A fall finder sensor normally consolidates gyroscopic figuring. Here the three pivot of an individual's position is determined. At the point when an individual falls these tomahawks contrast, bringing about discovery of the equivalent.

\section{PROPOSED SYSTEM}

The paper proposes a gadget which would assist the unfortunate casualty with alerting others during crisis circumstances and furthermore share area of themselves. The proposed model can be turned ON by an activity of human hand (switch). This is on the grounds that we can't be certain that an unfortunate casualty will consistently have opportunity to turn on the framework physically. To turn it ON the framework proposed has three alternatives for the person in question.

Published By:

Blue Eyes Intelligence Engineering

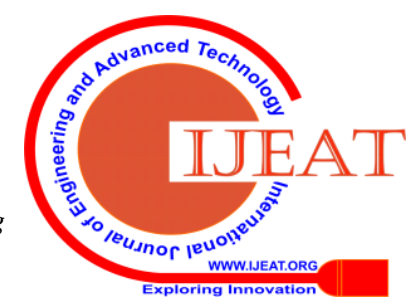

\& Sciences Publication

(C) Copyriaht: All riahts reserved. 
In the event that the unfortunate casualty has the opportunity to turn ON the framework, at that point a straightforward switch can be utilized to turn the framework ON. At the point when a lady is assaulted or in a perilous circumstance, she can press the switch and activate taser.

In the interim, the GSM would begin sending the frenzy message to the telephone numbers previously put away. Until the framework is reset these messages would be sent for at regular intervals.

This consolidates a switch as a choice to turn ON the framework when unfortunate casualty feels compromised. During health related crisis a switch can likewise be utilized. The individual at the opposite end has a telephone with Google maps App that would find the injured individual's area. The muscles of the suspect are temporarily tampered with the help of shock circuit. The bright light when exposed to the people contracts it which leads to temporary blank out of eye sight. When the switch is pressed not only light, GSM/GPS circuit is activated but also the short circuit is activated. The SIM808 GPS/GSM module sends latitude and longitude details via SMS.

The proposed framework is wanted to be non-Android remembering that the framework must be useful in any event, for youngsters. The majority of the items in advertise today are Android based. Size of the item is another significant factor that we can't undermine. This is on the grounds that; the armband must be less noticeable and unmistakable to other people. The fundamental test is the cost factor that should be considered as it is pivotal for the achievement of the item alongside an opportunity to advertise.

\section{BLOCK DIAGRAM}

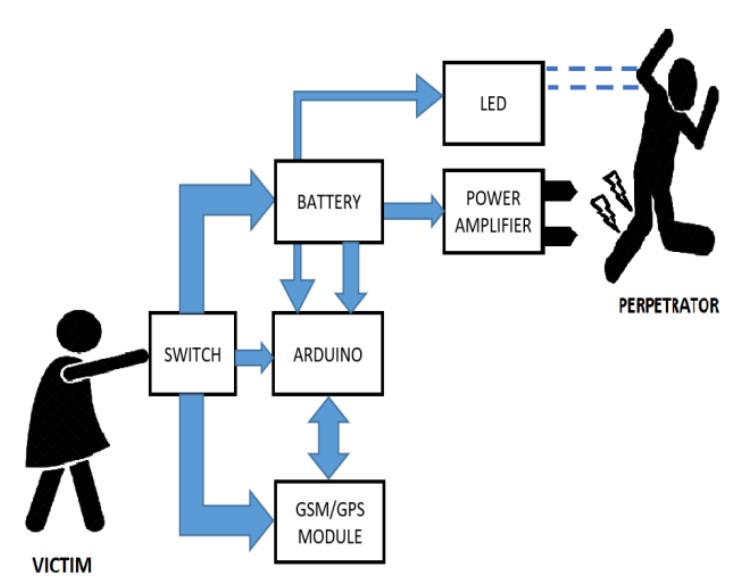

\section{IMPLEMENTATION \& RESULTS}

Women safety is the primary concern of this project thus we wanted to make this project simple to operate, easy to understand yet an effective self-defence device. We have utilized Arduino for processing the instructions and added external components such as light source with high luminosity in order to blank-out eyesight of the perpetrator since human pupil contract when exposed to bright light, a mini electroshock weapon is also implemented with help of $9 \mathrm{v}$ battery, step-up power module high voltage generator and two metal contacts which produces output voltage up to $5 \mathrm{KW}$.

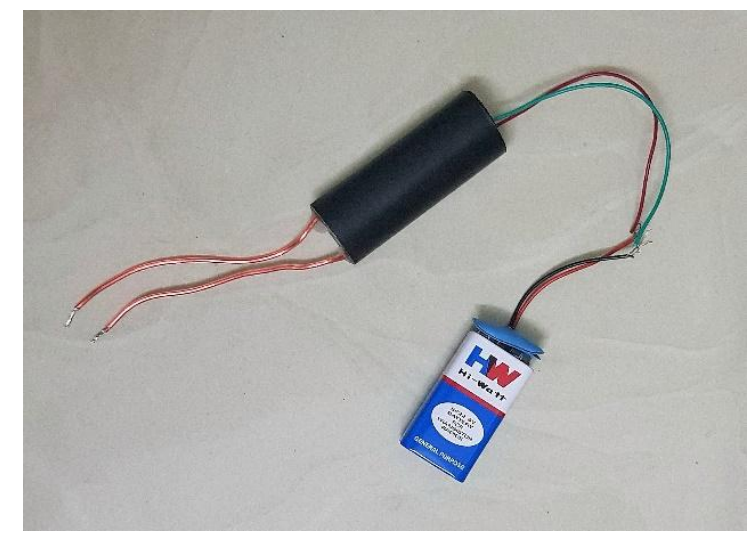

This temporarily disrupts muscle function or inflicts pain without causing significant injury. With help of SIM808 GSM/GPS module, the women can either send her location details to the cared ones or make them realise that currently she is not safe.

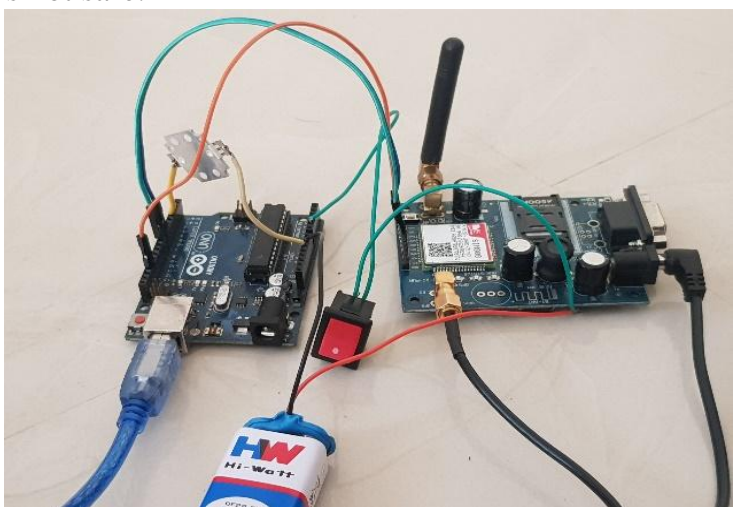

When the women press the switch, it activates the SIM808 GSM/GPS module along with the tracer circuit thus the person is delivered shock and family members would come to know that she is in danger.

At initial stage of our project we connected Arduino with SIM808 GSM/GPS module and included number of guardian in it so that using GPS the location is tracked and using GSM message that she is in danger and longitude, latitude of the location are also shared to the guardian. At next stage we added light source to the circuit and connect the previous GSM/GPS circuit with battery. Necessary adjustment and changes in code were also made.

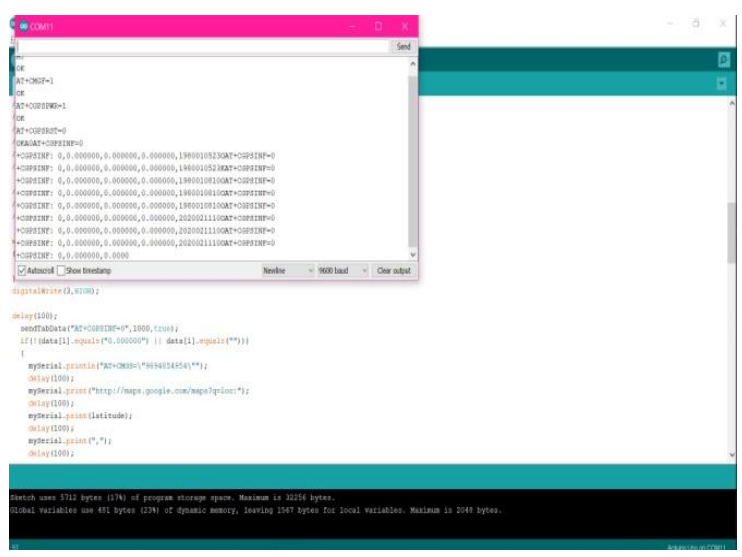

At final stage we built a tracer circuit with the voltage of $9 \mathrm{v}$ step-up with help of high voltage generator with sufficient voltage to warn the perpetrator that he is messing with wrong person.

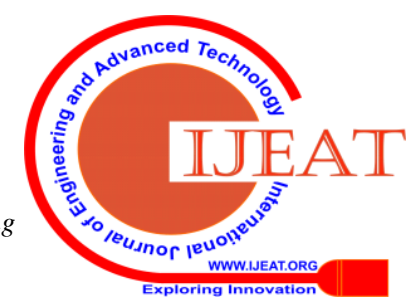


Finally, all the three individual modules are integrated into a single project with Arduino acting as the brain of the project since it process all instructions. We can make change in code in-order to change the latency of light either into a continuous bright light to blinking light. Being on safe side we can add additional numbers too so that when that particular number is not reachable we have additional number to contact. The intensity of voltage can also we varied by varying the range of high voltage generator. Keeping the luminosity factor in mind we are using SMD LED instead of ordinary LED. The surface mounted devices LED are special type of high power LED. The wire connections are also properly checked and maintained.

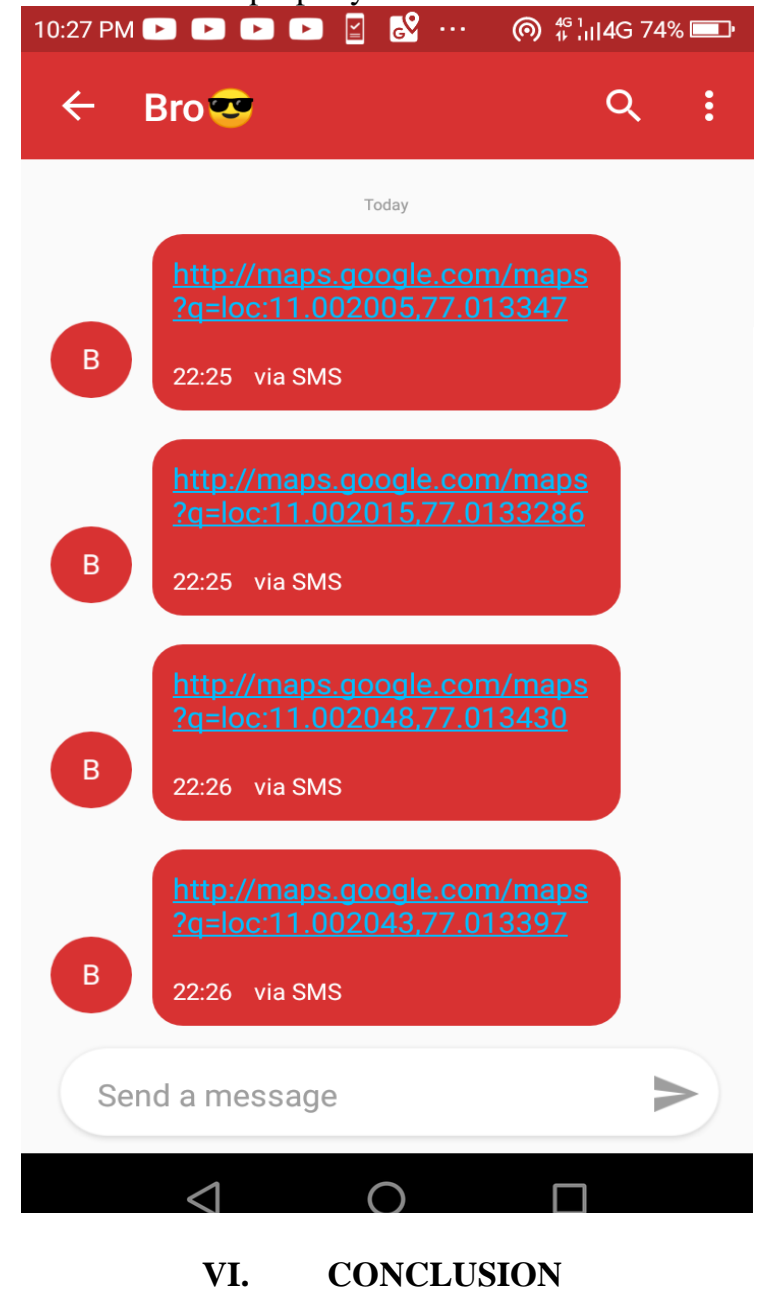

The task would help in upgrading the security and wellbeing of all depressed and goaded ladies and youths. This we accept would assist one with feeling verified as well as help the law implementing specialists to uncover the disguising guilty parties. This task might be a bit nearer for us to upgrade our Social Security.

\section{ACKNOWLEDGMENT}

I want to express gratitude toward, Ms.R.Priya, Assistant professor and Dr.Udaiya Kumar, Professor and Head of the, Department of ECE, SKCT, Coimbatore for their direction, support, in doing this work.

\section{REFERENCES}

1. Jiewen Zheng; Inst. of Med. Prepare., Acad. of Mil. Drug. Sci., Tianjin, China ;Guang Zhang ; Taihu Wu, Design of Automatic Fall Detector for Elderly Based on Triaxial Accelerometer ; Bioinformatics and Biomedical Engineering , 2009. ICBBE

\section{AUTHOR PROFILE}

Mahendar singh rajpurohit is a student of Sri Krishna college of technology in which he has completed his bachelors of engineering in electronics and communication engineering . He has an overall CGPA of 8.8 and has excellent knowledge in communication stream. With excellent academic results in $10^{\text {th }}, 12^{\text {th }}$ and UG ,he has planned to pursue MBA in future due to his curiosity in the field of finance and marketing. He was born in Rajasthan but fell in love with Dravidian culture which is the reason why he has been staying in Tamilnadu for past 20 years and is planning to stay for ever.

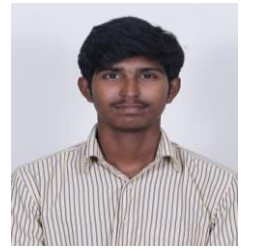

K K Pradeep raj is a student of Sri Krishna college of technology in which he has completed his bachelors of engineering in electronics and communication engineering. He has an overal CGPA of 6.8 and has satisfactory knowledge in communication stream. Pradeep Raj has been working on to build skills which would match him to the profile of IPS. He has been sincerely working on government exams in-order to get chance to serve the nation. He has completed his schooling in Madurai and UG in Coimbatore.

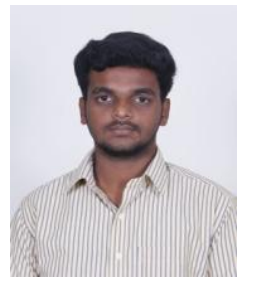

S Kabilbalan is a student of Sri Krishna college of technology in which he has completed his bachelors of engineering in electronics and communication engineering. He has an overal CGPA of 7.0 and has satisfactory knowledge in communication stream. Kabilb alan has been working on to build skills which would match him to the profile of IAS. 
He has been sincerely working on government exams in-order to get chance to serve the nation. He has completed his schooling in Madurai and UG in Coimbatore.

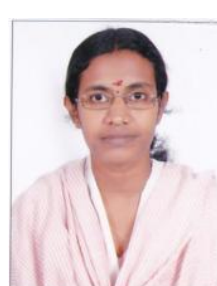

Ms. R.Priya is an Assistant professor in the department of electronics and communication engineering at Sri Krishna college of technology. She is considered as one of the best professor in Sri Krishna college of technology. With deterministic attitude she has helped and transformed life of many engineers. She is known for her simplistic teaching that makes the tough subjects seem easier which is the reason why she is favourite professor of many students. 